\title{
Didáctica de la geografía. Prácticas escolares y formación de profesores
}

\author{
Reseña elaborada por:
}

\section{Carlos Alberto Zambrano Barrera ${ }^{1}$}

Fernández, María y Gurevich, Raquel (directoras) (2014).

Didáctica de la geografía. Prácticas escolares y formación de profesores. Editorial Biblos.

Buenos Aires, Argentina.

A disciplina de geografia que acontece no ensino Tem marcas que são as características próprias, Construídas ao longo da sua trajetória de ensino e de aprendizagem Agregadas a ciência geográfica que com os avanços da pesquisa Foi ampliando o conhecimento da terra.

Helena Copetti Callai

El libro Didáctica de la Geografía. Prácticas escolares y formación de profesores ve la luz por vez primera en 2014, año en el que se celebró el III Coloquio Internacional de Investigadores en Didáctica de la Geografía, en la ciudad de Buenos Aires, y cuyo resultado se plasma en cada uno de los capítulos del libro.

Una treintena de personas, entre investigadores y docentes, muestran el resultado de sus trabajos a lo largo de los 15 capítulos que componen este volumen, los cuales se distribuyen en tres partes:

- Investigación, didáctica y enseñanza de la geografía en América Latina.

- Prácticas docentes y formación profesional en geografía.

- Saberes, experiencias y valoraciones de la geografía escolar.

1 Docente, Universidad EAN, Bogotá.
En la enseñanza y el aprendizaje de la geografía existen divergencias y convergencias; particularmente, en el ámbito latinoamericano. Esa es una de las particularidades de este libro: muestra las divergencias investigativas, las cuales, en vez de alejar a los estudiosos del tema, los acercan, en la medida en que las discusiones se enriquecen y ofrecen perspectivas novedosas en el desarrollo de la ciencia. Además, permiten un diálogo franco y abierto entre investigación, didáctica y prácticas escolares.

El punto de partida es la crisis de los contenidos de la geografía cuando es abordada desde el "imaginario" de ser el escenario de la toponimia. Por ello:

(...) é premente que se busque encontrar as formas de trabalhar na escola de modo a construir um conhecimento que seja significativo, que tenha a ver com a vida do estudante e que o desafie a querer conhecer mais e se reconhecer em sua identidade e pertencimento tendo a cidade (o lugar onde vive) como lócus central. ${ }^{2}$ (Callai, p. 69).

2 Todas las citas corresponden al libro reseñado. 
Esta crisis plantea la necesidad de investigar: "Às questões que envolvem concepções docentes sobre Geografia, tanto a científica quanto a escolar" ya que estas "...revelam as diferentes naturezas das mesmas e, também, a complexidade da temática” (Lastória y Fernandes, p. 99).

Al tiempo que se van identificando estas "concepções docentes", emergen nuevos interrogantes acerca de lo que debe y puede ser el objeto de estudio en la geografía como disciplina, y que se transforma en proceso de formación tanto para el futuro docente como para sus estudiantes en la práctica del ejercicio profesional como docentes. Términos como sociedades sustentables (Gurevich y Fernández, p. 17), democracia, ciudadano, espacio público, lugar y usos del suelo (Pulgarín, Tamayo y Castellar), pensamiento espacial sistémico y desarrollo sustentable (Araya y Herrera, p. 111), entre otros, saltan a la palestra para abrir nuevos horizontes conceptuales, teóricos y didácticos.

Estos caminos conceptuales están llenos de vericuetos, lo que obliga a pensar en la mejor forma de recorrerlos, y ello, a su vez, hace necesario ampliar el campo de investigación hacia la didáctica. En dicho campo es posible apreciar situaciones en las cuales "Los nuevos contenidos se yuxtaponían con los tradicionales y las formas de enseñar no variaban demasiado" (Zenobi, p. 77). Hay la urgente necesidad de introducir cambios significativos en la didáctica, de tal suerte que se logre la relación entre el estudiante, el conocimiento y la vida cotidiana.

Esa relación implica el desarrollo del pensamiento espacial sistémico, como camino expedito para que el estudiante tome "decisiones adecuadas con el medio ambiente y el espacio geográfico" (Araya y Herrera, p. 111), con lo cual los autores invitan a pensar para qué se enseña y se aprende la geografía. La respuesta no es unívoca: es polisémica; o sea, diverge y enriquece. El rumbo se encamina al “(...) desarrollo de actitudes ciudadanas responsables, agentes comprometidos y sensibles a la problemática ambiental y social” (Araya y Herrera, p. 124).

Para lo anterior, la investigación participativa se constituye en el eje central del proceso investigativo. El docente en ejercicio, tanto como el docente en formación, hace explicitas sus concepciones, sus imaginarios y sus enfoques para tomarlos como referencias al momento de hacer propuestas de innovación didáctica (Araya y Herrera; Ajon, Bachmann y Souto). Propuestas que implican la "selección de contenidos (...) elaboración de secuencias didácticas (...) el uso de estudios de casos (...) fuentes no tradicionales (...) narrativas", entre otros (Ajon, Bachmann y Souto, p. 137).

Es, precisamente, este último aspecto el que adquiere una dimensión espacial, en la medida en que se atribuye un significado al espacio, ya sea el del aula, el de la escuela, el del entorno del estudiante o el del mundo. El grupo Geopaideia propone revisar la legislación que se ha promulgado en torno a la enseñanza de las Ciencias Sociales; en particular, de la geografía. Ello, por cuanto esta "se ha insertado como saber para consolidar proyectos de orden nacional en relación con el conocimiento del territorio" (Grupo Geopaideia, p. 149). También es importante incluir la narrativa de los "(...) docentes, de las instituciones educativas y de la sociedad en general” (Grupo Geopaideia, p. 150), la cual se representa en los imaginarios de lo que es y lo que no es la geografía escolar.

Por lo cual el grupo plantea diversos retos para la formación de formadores, los cuales se presentan acá en forma de interrogantes: ¿cómo lograr un adecuado equilibrio entre la formación en investigación y la formación en el campo disciplinary la formación en didáctica de los docentes? ¿Cuál es la relación entre la formación disciplinar y la interdisciplinaridad en la formación docente? Y, finalmente, ¿cómo lograr la transformación de los imaginarios sociales sobre el aprendizaje de la geografía a partir de la formación docente en las universidades?

Estos cambios implican que el docente debe reconocerse como sujeto de significados. Es decir, que es un actor que construye subjetividades, empezando por la propia. Por eso es relevante partir de “(...) las representaciones que los profesores de geografía" tienen sobre diversos temas; en particular, sobre "la diversidad cultural de sus estudiantes", situación que se genera en un ambiente de interculturalidad (Trigo, Rotondaro, Flores y Flouch, p. 174). Los autores proponen ir más allá de la simple identificación, por lo que se propone establecer la relación entre las representaciones y el abordaje de la interculturalidad en el aula de clase acerca de las consecuencias que estas concepciones representan para la didáctica, la selección de temas y las dinámicas propias de las clases.

Por lo anterior, la didáctica de la geografía se empieza a orientar hacia un aspecto de interés creciente: ¿qué necesita la sociedad actual? ¿Cómo estas necesidades se relacionan con los saberes escolares? (Quintero, Saidon y Bachmann). Interrogantes que requieren una reflexión profunda antes de dar una respuesta definitiva.

El libro Didáctica de la geografía. Prácticas escolares y formación de profesores fue escrito en la diversidad, la divergencia y la convergencia. Ofrece un panorama de lo que se viene haciendo en materia de la didáctica y de la formación del profesorado en diversas regiones y de diversos modos.

Finalmente, es posible decir que este libro tiene un ligero tinte "rayuelesco", si se permite el término. De acuerdo con las instrucciones dadas al inicio de la novela de Cortázar, el lector puede empezar en el capítulo uno y seguir la secuencia lineal hasta el último capítulo. O puede leer los capítulos en cualquier orden. 0 puede crear su propio tablero de dirección y construir su propia secuencia. Porque cada capítulo es una unidad en sí misma, y todos los capítulos, en conjunto, evidencian la riqueza de la divergencia en la didáctica de la geografía. 